\title{
N-3 Polyunsaturated fatty acid therapy improves endothelial function and affects adiponectin and resistin balance in the first month after myocardial infarction
}

\author{
Katarzyna Mizia-Stec ${ }^{1}$, Maciej Haberka ${ }^{1}$, Magdalena Mizia ${ }^{1}$, Artur Chmiel', Klaudia Gieszczyk
} Bartosz Lasotaํ, Joanna Janowska², Barbara Zahorska-Markiewicz², Zbigniew Gąsior ${ }^{1}$

1Department of Cardiology, Medical University of Silesia, Katowice, Poland 2Department of Pathophysiology, Medical University of Silesia, Katowice, Poland

Submitted: 2 June 2010

Accepted: 27 August 2010

Arch Med Sci 2011; 7, 5: 788-795

DOI: 10.5114 /aoms.2011.25553

Copyright () 2011 Termedia \& Banach

\author{
Corresponding author: \\ Katarzyna Mizia-Stec MD \\ $\mathrm{PhD}$ \\ 45/47 Ziołowa \\ 40-635 Katowice, Poland \\ Phone: +48 322527407 \\ Fax: +48322523032 \\ E-mail: kmizia@op.pl
}

\begin{abstract}
Introduction: N-3 Polyunsaturated fatty acids (n-3 PUFA) exert clinical beneficial effects in patients after acute myocardial infarction (AMI). However, their exact mechanisms of action are not well recognized yet. Our aim was to evaluate effects of early introduced n-3 PUFA supplementation on endothelial function and serum adipokine concentrations in patients with AMI.

Material and methods: Thirty-eight patients with AMI and successful coronary stent implantation were randomized to the study group (PUFA group: $n=19$; standard therapy + PUFA $1 \mathrm{~g}$ daily) and the control group (control group: $n=19$; standard therapy). The study group patients were given n-3 PUFA (Omacor $1 \mathrm{~g}$ daily) starting from the $3^{\text {rd }}$ day of AMI. Ultrasound vascular indexes (flowmediated dilatation [FMD], nitroglycerine-mediated dilation [NMD]) and serum concentrations of adiponectin and resistin (ELISA) were evaluated before and after 30 days of pharmacotherapy.

Results: Comparison of the mean delta values (baseline/after 30 days of therapy) between groups revealed significant differences for delta FMD (PUFA 7.6 $\pm 12.4 \%$ vs. control $-1.7 \pm 10.5 \%, p=0.019$ ) and delta resistin concentrations (PUFA 1.0 $\pm 3.8 \mathrm{pg} / \mathrm{ml}$ vs. control $-1.6 \pm 2.9 \mathrm{pg} / \mathrm{ml}, p=0.028$ ). Multiple linear regression analysis for all subjects revealed the n-3 PUFA supplementation $(r=10.933$, $p=0.004)$ and waist circumference $(r=-0.467, p=0.01)$ as independent factors associated with delta FMD values ( $\mathrm{R}$-adjusted $0.29 ; p=0.002$ ).

Conclusions: Early and short-term n-3 PUFA supplementation in AMI with successful primary $\mathrm{PCl}$ and optimal pharmacotherapy improves endothelial function. However, increased resistin serum levels observed after 1-month n-3 PUFA supplementation merits further investigations.
\end{abstract}

Key words: polyunsaturated fatty acids, adiponectin, resistin, endothelial function, myocardial infarction.

\section{Introduction}

Numerous epidemiological and clinical studies have demonstrated that n-3 polyunsaturated fatty acids (PUFA) - eicosapentaenoic (EPA) and docosahexaenoic (DHA) acids - affect several cardiovascular endpoints with significant clinical effects in patients after acute myocardial infarction (AMI) $[1,2]$. However, despite a large number of studies on $n-3$ PUFA use in coronary artery disease (CAD), observations provided in an early phase of $\mathrm{AMI}$ with potential preclinical effects and potential mechanisms responsible 
for cardiovascular benefits are limited. The GISSIPrevenzione study showed that the early effects of n-3 PUFA supplementation were statistically significant after a 3-month period - patients were enrolled in the study up to 3 months from an MI and those benefits were based on clinical findings [1]. We might assume that some of the clinical effects could have significantly improved earlier than after 3 months. This is especially important because according to recently published data a short (1 month) n-3 PUFA therapy significantly potentiated platelet response to clopidogrel after percutaneous coronary intervention ( $\mathrm{PCl}$ ) [3]. Thus the issue of the early pleiotropic effects of $n-3$ PUFA supplementation is currently of high interest.

Patients with acute coronary syndrome (ACS) reveal numerous pathophysiological abnormalities, including decreased nitric oxide (NO) bioavailability, which is reflected in endothelial dysfunction [4]. In the literature there are inhomogeneous data on $\mathrm{n}-3$ PUFA intake and values of flow-mediated dilatation (FMD) - an ultrasound non-invasive index of endothelial function as well as an overall risk factor reflecting future prognosis and therapeutic interventions [5-7]. A significant improvement in endothelial function after n-3 PUFA supplementation was observed in some primary prevention clinical studies with no effects after AMI, which suggests the distinctiveness of n-3 PUFA effects in different populations [7-9].

On the other hand, a growing body of evidence suggests that adipose tissue is considered to be an important organ that secretes adipokines and is involved in the development of endothelial dysfunction and cardiovascular and metabolic diseases [10, 11]. N-3 PUFA supplementation may potentially modify both the activities of both proand anti-atherosclerotic adipokines. Adiponectin constitutes the main anti-atherosclerotic adipokine, and has a wide range of metabolic effects: it inhibits hepatic gluconeogenesis, improves oxidation of muscle fatty acids and insulin sensitivity, and increases HDL cholesterol synthesis. Moreover, adiponectin affects endothelial cells, reveals antioxidative effects, suppresses the expression of several proinflammatory cytokines and modulates vascular remodelling [12-15]. Resistin is a relatively new pro-atherosclerotic adipocyte-derived cytokine that affects glucose and lipid metabolism, thereby resulting in insulin resistance [13]. Experimental studies provide incoherent observations on the final cardioprotective or cardiodestructive role of resistin in AMI [16].

We aimed to explore whether early initiated 30-day n-3 PUFA therapy exerts an influence on ultrasound endothelial function parameters, adiponectin and resistin serum levels in patients with AMI.

\section{Material and methods}

Thirty-eight patients with AMI and successful coronary stent implantation were included in the study and randomly assigned to receive n-3 PUFA (Omacor; $1 \mathrm{~g} /$ day omega-3-acid ethyl esters = 465 mg EPA + 375 mg DHA; Solvay Pharma, Hanover, Germany) introduced from the $3^{\text {rd }}$ day of AMI (PUFA group; $n=19 ; F / M=5 / 14$, age: $56 \pm 8$ years; STEMI: 74\%; TIMI 3: 100\%; standard therapy + PUFA $1 \mathrm{~g}$ daily) or control group (control group; $n=19 ; \mathrm{F} / \mathrm{M}=3 / 16$; age: $62 \pm 9$ years; STEMI: $58 \%$; TIMI 3: $100 \%$; standard therapy).

All patients were diagnosed with typical chest pain, dynamic ST changes in the electrocardiogram, a new regional wall motion abnormality in the echocardiography and significantly increased cardiac markers exceeding the $99^{\text {th }}$ percentile of the upper reference limit (URL) (CPK - creatine phosphokinase, CPK-MB - creatine phosphokinase-myocardial bound isoenzyme, troponin I).

The following ultrasound endothelial function indices were obtained at the baseline ( $3^{\text {rd }}$ day of $\mathrm{AMI})$ and after one month (30 \pm 1 days) of therapy: brachial artery diameter (BAd), FMD, NMD and serum levels of adiponectin and resistin (ELISA).

The pharmacotherapy given to all patients (standard therapy) followed the European Society of Cardiology (ESC) recommendations: $75 / 100 \mathrm{mg}$ acetylsalicylic acid, $75 \mathrm{mg}$ clopidogrel, $40 \mathrm{mg}$ atorvastatin, a $\beta$-blocker and angiotensin-converting enzyme inhibitors (ACE-I) adjusted to heart rate and blood pressure (Table I).

None of the participants had been taking any $n$ 3 PUFA or other PUFA medications before. All patients declared $\leq 1$ fish meal weekly in the past.

Table I. Pharmacotherapy in study groups

\begin{tabular}{|lccc|}
\hline Drug & $\begin{array}{c}\text { PUFA group } \\
\text { (n-3 PUFA) } \\
(N=19)\end{array}$ & $\begin{array}{c}\text { Control } \\
\text { group } \\
(N=19)\end{array}$ & Value of $p$ \\
\cline { 2 - 3 } & No. (\%) & No. (\%) & \\
\hline Acetylsalicylic acid & $19(100 \%)$ & $19(100 \%)$ & NS \\
\hline Clopidogrel & $19(100 \%)$ & $19(100 \%)$ & NS \\
\hline Atorvastatin & $19(100 \%)$ & $19(100 \%)$ & NS \\
\hline$\beta$-Adrenolytics & $19(100 \%)$ & $19(100 \%)$ & NS \\
\hline $\begin{array}{l}\text { Angiotensin- } \\
\text { converting } \\
\text { enzyme inhibitors }\end{array}$ & $19(100 \%)$ & $19(100 \%)$ & NS \\
\hline Diuretics & $9(47 \%)$ & $7(37 \%)$ & NS \\
\hline $\begin{array}{l}\text { Dihydropyridine } \\
\text { calcium channel } \\
\text { blockers }\end{array}$ & $2(11 \%)$ & $4(22 \%)$ & NS \\
\hline
\end{tabular}

Data are expressed as mean $\pm S D$ and as medians for abnormally distributed variables 
Compliance with the study drug (Omacor) supplementation was determined by a capsule count and patients' reports and all individuals included in the PUFA group ingested all doses as instructed before the study.

The exclusion criteria included the following: acute and chronic inflammatory diseases (in the preceding 3 months), cigarette smoking within $12 \mathrm{~h}$ before examination, $2^{\text {nd }}$ and $3^{\text {rd }}$ degree hypertension according to ESC guidelines, history of acute coronary syndrome or cerebral infarction within 6 months prior to study enrolment, history of coronary revascularization (percutaneous coronary angioplasty or cardiosurgery), general surgery within 6 months prior to study enrolment, acute heart failure within 6 months prior to study enrolment, chronic heart failure, diabetes (previously diagnosed and/or treated, newly diagnosed: clinical symptoms of hyperglycaemia with casual plasma glucose $\geq 200 \mathrm{mg} / \mathrm{dl}$, fasting plasma glucose $\geq 126 \mathrm{mg} / \mathrm{dl}$ or diabetes - 2-h plasma glucose $\geq 200 \mathrm{mg} / \mathrm{dl}$ in oral glucose tolerance test performed if necessary), obesity (defined as body mass index [BMI] $\left.>35 \mathrm{~kg} / \mathrm{m}^{2}\right)$, acute or chronic inflammatory, autoimmunological or infectious diseases, liver dysfunction (alanine aminotransferase $>3 \times U R L$, bilirubin > $1.2 \mathrm{mg} / \mathrm{dl}$ ), renal (Cockcroft-Gault glomerular filtration rate $<60 \mathrm{ml} / \mathrm{min}$ ) or pancreatic (amylase $>1.5 \times$ URL) dysfunction, gastrointestinal tract disorders or psychological diseases in the preceding 6 months hindering study participation or affecting evaluated parameters. Additionally, patients with a history of malignancies in the preceding 5 years were excluded. Finally, individuals with severe dyslipidaemia (total cholesterol $\geq 320$ $\mathrm{mg} / \mathrm{dl}$ or low density lipoprotein cholesterol $\geq 240$ $\mathrm{mg} / \mathrm{dl}$, or triglycerides $\geq 400 \mathrm{mg} / \mathrm{dl}$ ) requiring higher doses of statins or combination pharmacotherapy or uncontrolled arterial hypertension and prior long-term therapy with drugs with a potential influence on adipokines (e.g. hypolipidaemic, ACE inhibitors, angiotensin receptor antagonists, antiinflammatory, anti-infectious, immunomodulatory drugs, hormone replacement therapy) were not included. Patients with significant abnormalities in laboratory tests defined as red blood cells $<4.2$ $\times 10^{6} / \mu \mathrm{l}$, haemoglobin $<12 \mathrm{~g} / \mathrm{dl}$, platelet count $<100 \times 10^{3} / \mu$ l were excluded.

The clinical characteristics of patients consisted of medical history (familial diseases, concomitant diseases, pharmacotherapy used, dietary habits and smoking status), physical examination, standard laboratory tests (including lipidograms), adiponectin and resistin serum concentration evaluation, and accessory investigations (electrocardiogram, echocardiography). Echocardiography was performed in all patients according to the standards of the European Society of Echocardiography.
All clinical data, accessory investigations, adiponectin and resistin serum levels were obtained at baseline ( $3^{\text {rd }}$ day of AMI) and after 30 days of therapy. The ultrasound measurements were performed in the morning after an overnight fast and $12 \mathrm{~h}$ off hypertension medications and smoking.

Subjects were recruited and completed the study at the Department of Cardiology at the Medical University of Silesia. The study protocol was approved by the local Silesian University of Medicine Ethics Committee and all individuals submitted written informed consent for the study procedures.

The following vascular ultrasonography techniques were used to assess the functional and structural remodelling of the vascular system

\section{Flow-mediated dilatation}

Endothelium-dependent FMD was assessed according to the standard techniques [17]. The measurements of brachial artery FMD were done in a quiet, temperature-controlled room, between 9 and $11 \mathrm{am}$. Patients were examined after at least 10-min rest; ultrasound examination was performed in a supine position. Expert investigators took measurements in a B-mode presentation. The brachial artery of the dominant forearm was visualized above the antecubital fossa in a longitudinal plane, with a sphygmomanometric cuff on the proximal part of the arm. The BAd was described as a minimal distance between " $m$ " lines, from the anterior to posterior wall of the artery. Images were acquired with an ECG gating, with measurements made in end diastole, which corresponds to the onset of the $R$ wave. The study was performed in three stages: 1) stage 1: baseline BAd and flow measurements were made, and an average was calculated for each subject; 2) stage 2: sphygmomanometer cuff was inflated to $200 \mathrm{mmHg}$ to occlude arterial inflow for 3 min; 3) stage 3: BAd and blood flow were measured and the mean of the values obtained during 50 to $60 \mathrm{~s}$ after cuff deflation was calculated. Taking these two measurements into consideration (baseline and after cuff deflation), FMD was calculated (percent increase of the artery diameter in comparison to baseline results). After a 10-min rest, a sublingual tablet of nitroglycerine (0.5 mg) was administered to determine the maximum obtainable exogenous vasodilatory response. The BAd and blood flow were measured following NTG, and NMD was determined (NTG-induced percent increase of the artery diameter). All FMD and NMD measurements were performed blind to the treatment with intra- and inter-observer variability in our lab $<8 \%$. 


\section{Blood sampling and laboratory measurements}

Blood samples were collected from each subject after a 10-h fast. After centrifugation, aliquots were frozen at $-80^{\circ} \mathrm{C}$ until assayed.

The measurements of adiponectin and resistin concentration were performed by ELISA Kit (R\&D Systems, USA). Lipid parameters (total serum cholesterol, HDL cholesterol, LDL cholesterol, triglycerides) were measured using commercially available test kits (Point Scientific Inc. Michigan, USA).

\section{Statistical analysis}

All text and table results are expressed as means \pm standard deviation (SD) for normally and as medians for abnormally distributed variables or number and percentage. The results' normal distribution was analysed with the KolmogorovSmirnov test. Baseline clinical parameters and the results of accessory investigations were compared using two-sample $t$-tests for normally distributed continuous variables (Student's t-test); in case of non-normal distribution, the Mann-Whitney U test was used. Wilcoxon test or paired samples $t$-test was performed to evaluate the significance of parameters' changes over time. Spearman rank model was used for correlation analysis of the baseline parameters and the parameters obtained after 30-day therapy. The Pearson model was used to determine the relationships between the delta values of the variables (baseline/after 30-day therapy). To compare the change of adiponectin, resistin, FMD and NMD over time, the data were analysed as repeated measures analysis of variance, taking into account intervention factors and time. If the data were positively skewed, logarithmic transformation was used. Multivariable linear regression was used to assess independent predictors of the FMD, NMD, adiponectin and resistin concentrations as well as the delta values of the variables. Variables related to the dependent factor $(p<0.2)$ in a univariate analysis were tested in a multiple regression analysis. If the correlation coefficients between potentially independent factors were beyond the interval -0.70 to 0.70 , one of them was excluded. A value $p<0.05$ was considered statistically significant.

\section{Results}

\section{Baseline parameters}

There were no significant differences between the two groups in regard to demographic or clinical characteristics (Table II) or pharmacotherapy used ("Materials and Methods", Table I).

The PUFA and the control groups did not differ significantly in baseline ultrasound vascular indexes:
BAd (PUFA - $4.2 \pm 0.4 \mathrm{~mm}$ vs. control $-4.3 \pm 0.7 \mathrm{~mm}$; $p=\mathrm{ns}$ ), FMD (PUFA - $7.3 \pm 6.2 \%$ vs. control -10.9 $\pm 6.5 \%$; $p=n s$ ), NMD (PUFA $-24.5 \pm 13.9 \%$ vs. control - $26.3 \pm 12.4 \% ; p=n s$ ) or baseline adiponectin (PUFA - median - $9.8 \mathrm{mg} / \mathrm{ml}$ vs. control - median $9.1 \mathrm{mg} / \mathrm{ml}, p=\mathrm{ns}$ ) and resistin (PUFA - median $4.6 \mathrm{pg} / \mathrm{ml}$ vs. control - median $-7.0 \mathrm{pg} / \mathrm{ml} ; p=\mathrm{ns}$ ) serum levels (Table III).

\section{Outcome data - 30-day evaluation}

There were no differences in the clinical outcome after 30-day therapy between the two

Table II. Baseline demographic and clinical characteristics of study patients

\begin{tabular}{|c|c|c|c|}
\hline Parameter & $\begin{array}{l}\text { PUFA group } \\
\text { (n-3 PUFA) } \\
(N=19)\end{array}$ & $\begin{array}{l}\text { Control } \\
\text { group } \\
(N=19)\end{array}$ & Value of $p$ \\
\hline & $\begin{array}{c}\text { Mean } \pm \text { SD } \\
\text { or No. (\%) }\end{array}$ & $\begin{array}{c}\text { Mean } \pm \text { SD } \\
\text { or No. (\%) }\end{array}$ & \\
\hline Age [years] & $56 \pm 8$ & $62 \pm 10$ & NS \\
\hline Female/male & $\begin{array}{l}5(26 \%) / \\
14(74 \%)\end{array}$ & $\begin{array}{l}3(19 \%) / \\
16(81 \%)\end{array}$ & NS \\
\hline Weight [kg] & $85 \pm 10$ & $83 \pm 8$ & NS \\
\hline Height $[\mathrm{cm}]$ & $173 \pm 7$ & $174 \pm 5$ & NS \\
\hline Waist [cm] & $102 \pm 9$ & $101 \pm 7$ & NS \\
\hline Hip $[\mathrm{cm}]$ & $103 \pm 6$ & $100 \pm 6$ & NS \\
\hline $\mathrm{BMI}\left[\mathrm{kg} / \mathrm{m}^{2}\right]$ & $27.2 \pm 3.2$ & $27.5 \pm 2.9$ & NS \\
\hline $\mathrm{TCh}[\mathrm{mg} / \mathrm{dl}]$ & $192.1 \pm 31.5$ & $183.7 \pm 30.5$ & NS \\
\hline $\mathrm{TG}[\mathrm{mg} / \mathrm{dl}]$ & $136.4 \pm 43.7$ & $128.9 \pm 47.3$ & NS \\
\hline $\mathrm{HDL}[\mathrm{mg} / \mathrm{dl}]$ & $43.4 \pm 15.4$ & $44.5 \pm 18.6$ & NS \\
\hline $\mathrm{LDL}[\mathrm{mg} / \mathrm{dl}]$ & $125.3 \pm 31.5$ & $113.7 \pm 29.0$ & NS \\
\hline Creatinine $[\mathrm{mg} / \mathrm{dl}]$ & $0.89 \pm 0.23$ & $0.96 \pm 0.24$ & NS \\
\hline CK $[U / I]$ & $1320 \pm 726$ & $942 \pm 630$ & NS \\
\hline CK-MB [U/I] & $153.5 \pm 105.1$ & $106.4 \pm 68.4$ & NS \\
\hline Troponin I [ng/ml] & $8.4 \pm 7.6$ & $8.5 \pm 6.3$ & NS \\
\hline STEMI/NSTEMI & $\begin{array}{c}14(74 \%) / \\
5(26 \%)\end{array}$ & $\begin{array}{l}11(58 \%) / \\
8(42 \%)\end{array}$ & NS \\
\hline Anterior wall & $6(32 \%)$ & $6(32 \%)$ & NS \\
\hline Lateral wall & $3(16 \%)$ & $3(16 \%)$ & NS \\
\hline Inferior wall & $8(42 \%)$ & $7(37 \%)$ & NS \\
\hline Indeterminate & $2(11 \%)$ & $3(16 \%)$ & NS \\
\hline Current smoking & $10(53 \%)$ & $10(53 \%)$ & NS \\
\hline Family history & $5(26 \%)$ & $4(22 \%)$ & NS \\
\hline Hypertension I & $14(74 \%)$ & $16(82 \%)$ & NS \\
\hline $\begin{array}{l}\text { Hospitalization } \\
\text { [days] }\end{array}$ & $6.0 \pm 1.7$ & $5.8 \pm 1.4$ & NS \\
\hline
\end{tabular}

BMI - body mass index, TCh - total cholesterol, TG - triglycerides, $H D L$ - high-density lipoprotein, $L D L$ - low-density lipoprotein, $C P K$ - creatinine phosphokinase, $C P K-M B$ - creatinine phosphokinase $M B$-isoenzyme, STEMI - ST-elevated myocardial infarction 
Table III. Mean FMD and NMD values and mean adiponectin and resistin serum levels at baseline and after 30-day therapy - interaction of group and time

\begin{tabular}{|c|c|c|c|c|c|c|c|}
\hline & \multirow{2}{*}{\multicolumn{2}{|c|}{ n-3 PUFA group }} & \multirow{2}{*}{\multicolumn{2}{|c|}{ Control group }} & \multicolumn{3}{|c|}{ Value of $p$} \\
\hline & & & & & \multicolumn{3}{|c|}{ Source of variance } \\
\hline & $\begin{array}{c}\text { Baseline } \\
\text { evaluation }\end{array}$ & $\begin{array}{c}\text { 30-day } \\
\text { evaluation }\end{array}$ & $\begin{array}{c}\text { Baseline } \\
\text { evaluation }\end{array}$ & $\begin{array}{c}\text { 30-day } \\
\text { evaluation }\end{array}$ & Intervention (I) & Time $(\mathrm{T})$ & Interaction I x T \\
\hline FMD [\%] & $7.3 \pm 6.2$ & $14.9 \pm 10.4$ & $10.9 \pm 6.5$ & $9.1 \pm 7.9$ & 0.57 & 0.17 & 0.019 \\
\hline NMD [\%] & $24.5 \pm 13.9$ & $29.1 \pm 13.8$ & $26.3 \pm 12.4$ & $25.8 \pm 15.0$ & 0.69 & 0.39 & 0.27 \\
\hline $\begin{array}{l}\text { Adiponectin } \\
{[\mathrm{mg} / \mathrm{ml}]}\end{array}$ & $\begin{array}{c}12.5 \pm 7.8 \\
\text { Median: } 9.8\end{array}$ & $14.1 \pm 8.0$ & $\begin{array}{c}12.1 \pm 9.7 \\
\text { Median: } 9.1\end{array}$ & $19.4 \pm 12.7$ & 0.49 & 0.026 & 0.225 \\
\hline $\begin{array}{l}\text { Resistin } \\
{[\mathrm{pg} / \mathrm{ml}]}\end{array}$ & $\begin{array}{c}5.3 \pm 2.9 \\
\text { Median: } 4.6\end{array}$ & $6.4 \pm 4.0$ & $\begin{array}{c}6.4 \pm 3.0 \\
\text { Median: } 7.0\end{array}$ & $4.7 \pm 2.4$ & 0.71 & 0.56 & 0.028 \\
\hline
\end{tabular}

FMD - flow-mediated dilatation, NMD - nitroglycerine-mediated dilatation

groups. There were no sudden deaths or AMI in either group during 30-day observation. Rehospitalization due to recurrent angina was reported in 1 patient from the PUFA group and 2 controls. Angina symptoms were comparable between the groups (CCS $0-I$ ).

Ultrasound parameters of endothelial function and adipokine serum levels after 30-day therapy

Mean FMD (7.3 \pm 6.2 to $14.9 \pm 10.4 \%, p=0.02)$, but not NMD $(24.5 \pm 13.9$ to $29.1 \pm 13.8 \%, p=0.16)$ values increased significantly after 30-day therapy with n-3 PUFA. The FMD and NMD values did not change significantly among control patients (FMD: $10.9 \pm 6.5 \%$ to $9.1 \pm 7.9 \%, p=0.48$; NMD: 26.3 $\pm 12.4 \%$ to $25.8 \pm 15.0 \%, p=0.87$ ) (Figure 1 ). Finally, the PUFA group patients revealed significantly higher FMD values compared to the control group patients after 30 -day therapy $(14.9 \pm 10.4 \%$ vs. 9.1 $\pm 7.9 \% ; p=0.03)$. Comparison of the mean delta values (baseline/after 30-day therapy) for both groups revealed significant differences only for delta FMD (PUFA: $7.6 \pm 12.4 \%$ vs. control: $-1.7 \pm 10.5 \%$;

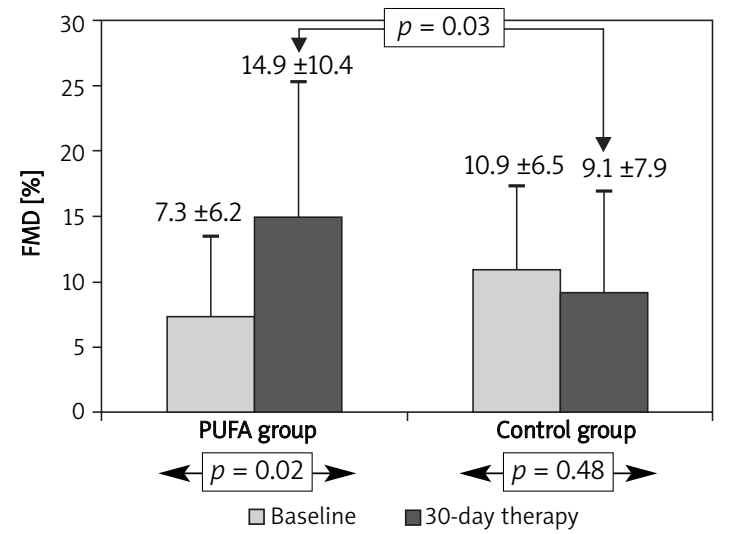

Figure 1. Mean FMD values at baseline and after 30-day therapy in PUFA and control groups
$95 \% \mathrm{Cl}$ of difference: 1.62 to $17.12 ; p=0.019)$ (Figure 2). The mean delta values of NMD were comparable for both groups (PUFA: $4.9 \pm 13.3 \%$ vs. control: $-0.6 \pm 14.5 \%, p=0.273)$.

There were no significant differences between adipokine serum levels measured at the baseline and after 30-day therapy in the PUFA group. However, a non-significant increase of adipokine levels was noted (adiponectin by $12.8 \%$ : $12.5 \pm 7.8$ to 14.1 $\pm 8.0 \mathrm{mg} / \mathrm{ml}, p=0.55$; resistin by $20.7 \%: 5.3 \pm 2.9$ to $6.4 \pm 4.0 \mathrm{pg} / \mathrm{ml}, p=0.35$ ). The control group patients revealed bidirectional statistically significant changes in serum concentrations of adipokines: $60.3 \%$ adiponectin increase $(12.1 \pm 9.7 \mathrm{mg} / \mathrm{ml}$ to 19.4 $\pm 12.7 \mathrm{mg} / \mathrm{ml} ; p=0.044)$ and $36.1 \%$ resistin decrease (6.4 $\pm 3.0 \mathrm{pg} / \mathrm{ml}$ to $4.7 \pm 2.4 \mathrm{pg} / \mathrm{ml} ; p=0.044)$. Finally, the PUFA group revealed lower (of borderline significance) adiponectin serum level compared to the Control group after 30-day therapy (14.1 \pm 8.0 $\mathrm{mg} / \mathrm{ml}$ vs. $19.4 \pm 12.7 \mathrm{mg} / \mathrm{ml} ; p=0.053$ ) (Table III). Comparison of the mean delta values (baseline/ after 30-day therapy) for both groups revealed significant differences only for the delta resistin concentration (PUFA: $1.0 \pm 3.8 \mathrm{pg} / \mathrm{ml}$ vs. control: $-1.6 \pm 2.9 \mathrm{pg} / \mathrm{ml}$; $95 \%$ $\mathrm{Cl}$ of difference: $0.33-4.99 ; p=0.028$ ) (Figure 3). The

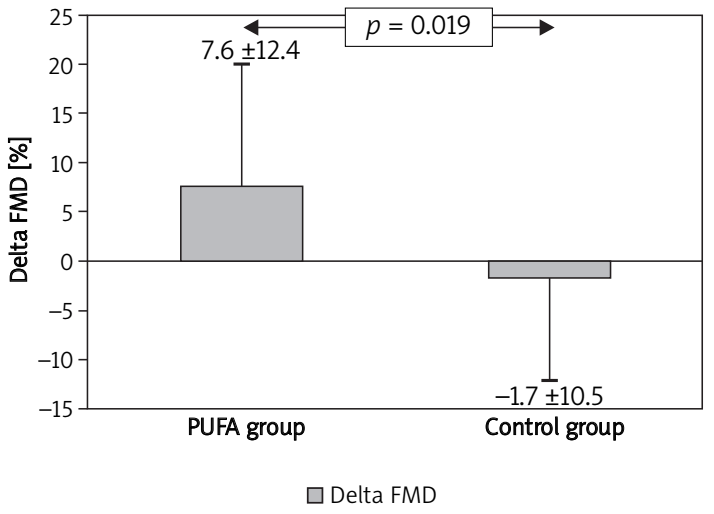

Figure 2. Mean delta FMD values in PUFA and control groups 


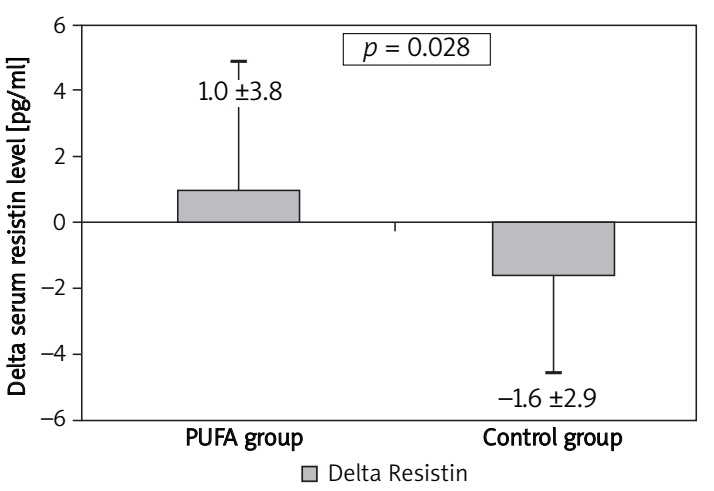

Figure 3. Mean delta serum resistin concentrations in PUFA and control groups

mean delta values of adiponectin levels were comparable for both groups (PUFA: $1.7 \pm 11.0 \mathrm{pg} / \mathrm{ml}$ vs. control: $7.3 \pm 17.2 \mathrm{mg} / \mathrm{ml}, p=0.296$ ).

Analysis of the intervention ( $n-3$ PUFA supplementation) and time revealed that $n-3$ PUFA supplementation significantly increased FMD values ( $p=0.019)$ and resistin serum levels $(p=0.028)$. Serum adiponectin levels significantly increased 30 days after $A M I$ regardless of $n-3$ PUFA therapy $(p=0.026)$.

Mean values of FMD, NMD and adipokine levels as well as the interaction of intervention and time are presented in Table III.

\section{Statistical analysis}

There were no significant correlations between FMD, NMD, adipokine serum concentrations and demographic, clinical or biochemical parameters. In the PUFA group, delta adiponectin concentrations correlated in a borderline significant manner to delta FMD values $(r=0.463, p=0.061)$ (Figure 4).

Multiple linear regression analysis for all subjects examined revealed the n-3 PUFA supplementation $(r=10.933, p=0.004)$ and waist circumference $(r=-0.467, p=0.01)$ as independent factors associated with delta FMD values (R-adjusted 0.29; $p=0.002)$.

\section{Discussion}

The major finding of our pilot randomized and prospective study was the demonstration that early introduced low dose n-3 PUFA supplementation on top of standard medical therapy compliant with current guidelines improves ultrasound vascular indexes of endothelial function. On the other hand, n-3 PUFA contributed to a significant increase in resistin serum levels. Adiponectin serum concentrations increased after $A M I$ regardless of n-3 PUFA therapy; however, the n-3 PUFA-induced FMD improvement seemed to be related to changes in the adiponectin level. On the other hand, control

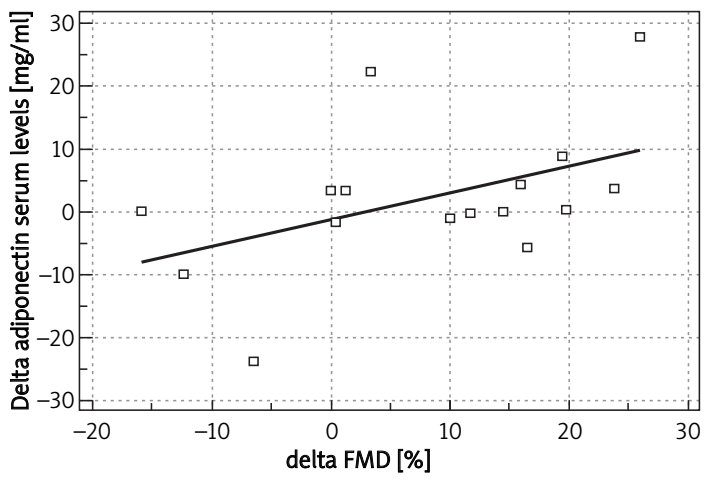

Figure 4. Correlation between delta adiponectin concentrations and delta FMD values in PUFA group $(r=0.463, p=0.061)$

patients subjected to standard pharmacotherapy without n-3 PUFA supplementation did not reveal any ultrasound endothelial function improvement. The study population was homogeneous and included AMI patients successfully treated with $\mathrm{PCI}$ selected according to strict and numerous exclusion criteria, burdened with a relatively low secondary prevention risk.

The improvement in FMD presented in our study indicates the favourable effects of early $n-3$ PUFA therapy in AMI. This is of great clinical importance because it suggests that n-3 PUFA might lower cardiovascular risk. The persistent decrease in FMD over the weeks following ACS has been found to carry negative predictive value [5]. However, pathomechanisms underlying FMD improvement in patients treated with n-3 PUFA are unclear. Recent studies suggest several potential explanations: decreased endothelium molecular adhesion and proinflammatory cytokines, circulating free fatty acid level changes [8], modulation of cell membrane function [18] or reduced oxygen-derived free radical formation by endothelial cells [19]. In our observation, an increase in FMD was independently associated with n-3 PUFA intervention and negatively with waist. We cannot conclude that abdominal obesity modifies the effect of PUFA supplementation. However, the presented study is the first suggesting a negative relationship between $n-3$ PUFA induced improvement in FMD values and a patient's waist circumference - an indicator of abdominal obesity. There have not been any published data on intervention-induced FMD changes in relation to obesity to date. In the literature there are only data on the relationship between obesity and FMD. According to some studies, obesity as a cardiovascular risk factor is associated with lower FMD and NMD [20]. However, there are also findings that FMD values in women with primary obesity were comparable to the values observed in controls with a normal BMI [21]. 
Adipokines evaluated in our study exerted potentially opposite effects on the cardiovascular system, endothelial function, and metabolic status, which might play a role in the clinical effects of n-3 PUFA supplementation in AMI. As we mentioned above, one important finding was that $n-3$ PUFA supplementation contributed to an increase in resistin levels. Additionally, we found that the serum adiponectin concentration increased regardless of the intervention. Moreover, a significant change in the direct concentrations of serum adipokines was noted in the control group. Interestingly, the AMIinduced adipokine "reaction", which was not modified by $n-3$ PUFA supplementation, was bidirectional, with a significant increase of adiponectin and a decrease in the resistin level. We would assume that our adipokine evaluations on the $3^{\text {rd }}$ and $30^{\text {th }}$ day were affected by an AMI-induced acute phase reaction and numerous pathophysiological abnormalities but the potential influence was similar in both groups.

Kojima et al. reported a significant decline of plasma adiponectin concentrations in patients hospitalized for AMI, with the lowest levels at $72 \mathrm{~h}$ after AMI, followed by a gradual increase [14], which was in accordance with our observations. It was demonstrated that adiponectin permeates to the subendothelial space and exerts antiatherosclerotic and tissue-repairing effects within the vascular wall, which seems to explain lower adiponectin concentrations in blood during acute phase reactions [14]. Both adiponectin and resistin have been demonstrated to follow opposite serum level patterns in different CAD populations, with the lowest adiponectin and highest resistin serum levels in AMI subjects as compared to respectively unstable angina and stable angina patients [24, 25].

Available evidence on potential effects of $n-3$ PUFA on adipokine levels in AMI is limited. Patel et al. found no significant influence of additional n-3 PUFA (1 g daily) supplementation on serum levels of adipokines (adiponectin, leptin and tumour necrosis factor $\alpha$ ) in post-Ml patients after 3-month treatment. There was an opposite direction of insulin fasting level changes during follow-up. An increase of insulin fasting concentrations in the n-3 PUFA group and decrease in the control group [26] were observed, which add to incoherent data of n-3 PUFA influence on insulin resistance in different subpopulations [27]. Moreover, it has been documented that resistin affected glucose and lipid metabolism, resulting in insulin resistance [13]. Our results showing a significant increase in resistin levels and lower adiponectin levels in the PUFA group may suggest an interesting explanation for these observations.
On the other hand, Micallef et al. demonstrated a significant adiponectin level increase and tumour necrosis factor alpha level decrease in hyperlipidaemic individuals subjected to a combination of n-3 PUFA and plant sterols supplementation, suggesting a favourable influence on metabolically active hormones in a different clinical setting [28].

Our potential limitation is a relatively small study sample, which partly results from numerous exclusion criteria. Nevertheless, we are presenting a pilot study in a research area of limited data. Finally, we measured adiponectin without distinguishing weight molecular forms of adiponectin. Our study did not document a distinct relation between FMD and adipokines. Because in the PUFA group delta adiponectin concentrations correlated in a borderline significant manner with delta FMD values, we might only hypothesize that FMD improvement could be mediated by adiponectin. On the other hand, the significant resistin changes in the PUFA group modify adiponectin/resistin balance; thus it should not be underemphasized but needs further evaluation.

In conclusion, early and short-term n-3 PUFA supplementation in AMI with successful primary $\mathrm{PCl}$ and optimal pharmacotherapy improves endothelial function assessed as FMD. Favourable FMD effects of $n-3$ PUFA in AMI may be mediated by adiponectin; however, its significant increase is not specific to n-3 PUFA intervention but is observed in all patients after AMI. An increase in resistin serum levels found in the n-3 PUFA group contributes to potential negative changes in adiponectin and resistin balance and may affect endothelial function. This finding merits further investigations of its relationship to metabolic and carbohydrate homeostasis.

\section{Acknowledgments}

The study was supported by a scientific grant from the Medical University of Silesia. No other sources of funding or study sponsors were involved.

\section{References}

1. Marchioli R, Barzi F, Bomba E, et al. Early protection against sudden death by $n-3$ polyunsaturated fatty acids after myocardial infarction: time-course analysis of the results of the Gruppo Italiano per lo Studio della Sopravvivenza nell'Infarto Miocardico (GISSI)-Prevenzione. Circulation 2002; 105: 1897-903.

2. Barylski M, Mikhailidis DP, Rysz J, Banach M. Nonpharmacological management after acute coronary syndromes. Arch Med Sci 2010; 6 (1A): S64-75.

3. Gajos G, Rostoff P, Undas A, Piwowarska W. Effects of polysaturated omega- 3 fatty acids on responsiveness to dual antiplateles therapy in patients undergoing percutaneous coronary intervention. J Am Coll Cardiol 2010; 55: 1671-8. 
4. Fichtlscherer S, Breuer S, Zeiher A. Prognostic value of systemic endothelial dysfunction in patients with acute coronary syndromes. Further evidence for the existence of the "vulnerable" patient. Circulation 2004; 110: 1926-32.

5. Vitale C, Cerquetani E, Wajngarten M, et al. In patients with coronary artery disease endothelial function is associated with plasma levels of C-reactive protein and is improved by optimal medical therapy. Ital Heart J 2003; 4: 627-32.

6. Petersen MM, Eschen RB, Aardestrup I, Obel T, Schmidt EB. Flow-mediated vasodilatation and dietary intake of $\mathrm{n}-3$ polyunsaturated acids in healthy subjects. Cell Mol Biol 2010; 56: 38-44.

7. Lee KW, Blann AD, Lip GY. Inter-relationships of indices of endothelial damage/dysfunction [circulating endothelial cells, von Willebrand factor and flow-mediated dilatation] to tissue factor and interleukin- 6 in acute coronary syndromes. Int J Cardiol 2006; 111: 302-8.

8. Rizza S, Tesauro M, Cardillo C, et al. Fish oil supplementation improves endothelial function in normoglycemic offspring of patients with type 2 diabetes. Atherosclerosis 2009; 206: 569-74.

9. Mozaffarian D, Rimm EB. Fish intake, contaminants, and human health: evaluating the risks and the benefits. JAMA 2006; 296: 1885-99.

10. Karra R, Becker RC. Biomarkers for outcome following acute coronary syndromes. Arch Med Sci 2010; 6 (1A): S55-S63.

11. Lyon CJ, Law RJ, Hsueh WA. Minireview: adiposity, inflammation, and atherogenesis. Endocrinology 2003; 144: 2195-200.

12. Karastergiou K, Mohamed-Ali V, Jahangiri M, Kaski JC. Adiponectin for prediction of cardiovascular risk? Br J Diabetes Vasc Dis 2009; 9: 150-4.

13. Karmazyn M, Purdham DM, Rajapurohitam V, Zeidan A. Signalling mechanisms underlying the metabolic and other effects of adipokines on the heart. Cardiovasc Res 2008; 79: 279-86.

14. Kojima S, Funahashi T, Sakamoto T, et al. The variation of plasma concentrations of a novel, adipocyte derived protein, adiponectin, in patients with acute myocardial infarction. Heart 2003; 89: 667-8.

15. Piestrzeniewicz K, Łuczak K, Goch JH. Factors associated with C-reactive protein at the early stage of acute myocardial infarction in men. Cardiol J 2009; 16: 36-42.

16. Gao J, Chang Chua C, Chen Z, et al. Resistin, an adipocytokine, offers protection against acute myocardial infarction. J Mol Cell Cardiol 2007; 43: 601-9.

17. Corretti MC, Anderson TJ, Benjamin EJ, et al. Guidelines for the ultrasound assessment of endothelial-dependent flow mediated vasodilatation of the brachial artery: a report of the International Brachial Artery Reactivity Task Force. J Am Coll Cardiol 2002; 39: 257-65.

18. Stillwell W, Wassall SR, Docosahexaenoic acid: membrane properties of a unique fatty acid. Chem Phys Lipids 2003; 126: 1-27.

19. Okuda Y, Kawashima K, Sawada T, et al. Eicosapentanoic acid enhances nitric oxide production by cultured human endothelial cells. Biochem Biophys Res Comm 1997; 232: 487-91.

20. Ayer JG, Harmer JA, David C, Steinbeck K, Seale JP, Celermajer DS. Severe obesity is associated with impaired arterial smooth muscle function in young adults. Obesity 2011; 19: 54-60.

21. Mizia-Stec K, Gasior Z, Zahorska-Markiewicz B, et al. The indexes of arterial structure and function in women with simple obesity: a preliminary study. Heart Vessels 2008; 23: 224-9.

22. Kawanami D, Maemura K, Takeda N, et al. Direct reciprocal effects of resistin and adiponectin on vascular endothelial cells: a new insight into adipocytokine-endothelial cell interactions. Biochem Biophys Res Commun 2004; 314: 415-19.

23. Verma S, Li SH, Wang CH, et al. Resistin promotes endothelial cell activation: further evidence of adipokineendothelial interaction. Circulation 2003; 108: 736-40.

24. Nakamura Y, Shimada K, Fukuda D, et al. Implications of plasma concentrations of adiponectin in patients with coronary artery disease. Heart 2004; 90: 528-33.

25. Qiao XZ, Yang YM, Xu ZR, Yang LA. Relationship between resistin level in serum and acute coronary syndrome or stable angina pectoris. J Zhejiang Univ Sci B 2007; 8: 875-80.

26. Patel JV, Lee KW, Tomson J, Dubb K, Hughes EA, Lip GY. Effects of omega-3 polyunsaturated fatty acids on metabolically active hormones in patients post-myocardial infarction. Int J Cardiol 2007; 115: 42-5.

27. Ramel A, Martinéz A, Kiely M, Morais G, Bandarra NM, Thorsdottir I. Beneficial effects of long-chain n-3 fatty acids included in an energy-restricted diet on insulin resistance in overweight and obese European young adults. Diabetologia 2008; 51: 1261-8.

28. Micallef MA, Garg ML. Anti-inflammatory and cardioprotective effects of $n-3$ polyunsaturated fatty acids and plant sterols in hyperlipidemic individuals. Atherosclerosis 2009; 204: 476-82. 